\title{
Intrauterine growth restriction in monochorionic-diamniotic twins
}

Rita de Cássia Alam Machado ${ }^{1}$, Maria de Lourdes Brizot ${ }^{1 *}$, Selzo Miyadahira ${ }^{1}$, Rossana Pulcineli Vieira Francisco ${ }^{1}$, Vera lúcia Jornada Krebs² ${ }^{2}$ Marcelo Zugaib ${ }^{1}$

${ }^{1}$ Department of Obstetrics, Hospital das Clínicas, University of São Paulo's Medical School, São Paulo, SP, Brazil ${ }^{2}$ Department of Pediatrics, Hospital das Clínicas, University of São Paulo's Medical School, São Paulo, SP, Brazil

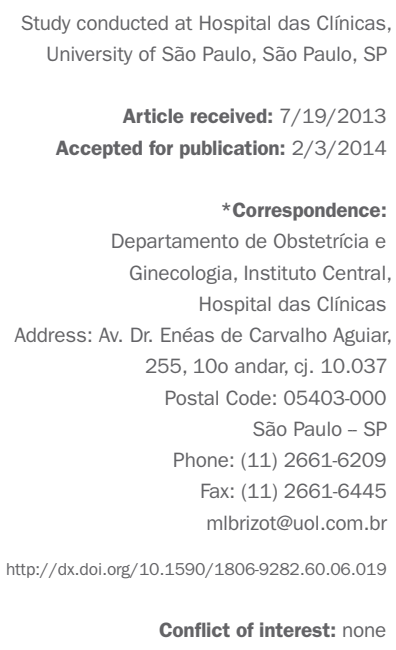

\section{SUMMARY}

Objective: to evaluate neonatal morbidity and mortality in monochorionic-diamniotic (MCDA) twin pregnancies complicated by selective intrauterine growth restriction (sIUGR) and non-selective intrauterine growth resctriction (nsIUGR).

Methods: neonatal morbidity parameters and mortality were analyzed in 34 twins with IUGR ( $<10^{\text {th }}$ percentile on twins' growth charts): 18 with sIUGR and 16 with nsIUGR. The sIUGR group was made up of 18 pregnancies in which growth was restricted in only one fetus $(\mathrm{n}=18)$. The nsIUGR group was composed of 8 pregnancies in which both fetuses presented restricted growth $(\mathrm{n}=16)$. Cases of twin-to-twin transfusion syndrome and fetal malformation were not included in the study.

Results: the MCDA twin pregnancies with sIUGR had a higher rate of orotracheal intubation $(p=0.001)$ and mechanical ventilation $(p=0.0006)$, as well as longer than average fasting time $(\mathrm{p}=0.014)$ compared to those in which the fetuses had nsIUGR. A higher incidence was also observed of types II and III umbilical artery Doppler velocimetry patterns in the sIUGR cases $(p=0.002)$. There was no significant difference between the two groups as to mortality during pregnancy and the neonatal period $(\mathrm{p}=0.09)$.

Conclusion: in MCDA twin pregnancies, sIUGR presents more severe umbilical artery Doppler velocimetry abnormalities and worse morbidity than nsIUGR.

Keywords: monozygotic twins, disease in twins, fetal growth retardation, laser Doppler flowmetry, morbidity, newborn infant.

\section{INTRODUCTION}

Intrauterine growth restriction (IUGR) in monochorionic pregnancies may affect one (selective IUGR, sIUGR) or both fetuses (non-selective IUGR, nsIUGR). However, when affecting both fetuses, IUGR morbidity, as compared with sIUGR morbidity in MCDA pregnancies, remains unknown. ${ }^{6}$

Selective intrauterine growth-restriction (sIUGR) affects $12-15 \%$ of monochorionic pregnancies. ${ }^{1}$ The monochorionic placenta structure accounts for most of the morbidity associated with these pregnancies. A greater incidence of marginal or velamentous umbilical cord insertion, unequal sharing of the placental bed, and unbalanced arterio-venous anastomoses, with consequent compensatory mechanisms, make each monochorionic placenta an individual and atypical arrangement., ${ }^{2,3}$
Gratacos et al., ${ }^{4}$ in 2004, initiated a series of studies demonstrating increased neonatal morbidity in monochorionic and diamniotic (MCDA) pregnancies affected by sIUGR with abnormalities in Doppler velocimetry. In 2007, Gratacos et al., ${ }^{5}$ comparing groups of sIUGR-affected MCDA pregnancies with different umbilical artery Doppler velocimetry patterns (normal Doppler, persistent absent or reversed end diastolic velocity flow, intermittent absent or reversed end diastolic velocity flow), reported, in the group with the latter pattern, a higher rate of intrauterine death (IUD) in the smaller fetus and of brain lesions in the larger fetus.

Gao et al., evaluated neonatal morbidity in 7 pregnancies with IUGR in both fetuses and 71 cases of sIUGR; the control group consisted of 217 cases without 
IUGR. In their study, conducted with a mixed sample of mono and dichorionic twin pregnancies, monochorionicity turned out to be a higher risk factor for IUGR, especially sIUGR ( $p<0.001)$. The groups associated with IUGR had a higher incidence of intrauterine death (IUD) and neonatal death $(\mathrm{ND})(\mathrm{p}<0.001)$.

However, there are no studies in the literature, specifically complicated by sIUGR compared to nsIUGR in MCDA pregnancies.

The aim of the current study was to evaluate prenatal evolution as well as perinatal morbidity and mortality in MCDA twin pregnancies complicated by sIUGR in contrast with nsIUGR.

\section{Methods}

This was a retrospective cohort study involving 34 monochorionic-diamniotic fetuses with IUGR $\left(<10^{\text {th }}\right.$ percentile, according to the Alexander et al. ${ }^{8}$ growth chart). We included cases that were followed up in our twin clinic and delivered in our hospital between 2004 and 2010. The study was approved by the Hospital's Ethics Committee $(0092 / 10)$.

The sIUGR group comprised 18 pregnancies in which only one fetus was restricted in growth $(n=18)$. The nsIUGR group was composed of 8 pregnancies in which both fetuses presented restricted growth $(n=16)$.

Cases with twin-to-twin transfusion syndrome (TTTS) ( $\mathrm{n}=43$ ), fetal malformation ( $\mathrm{n}=36)$, as well as three cases of sIUGR and IUD prior to 26 weeks that did not deliver in our institution and chorionicity not determined were not included in the study.

In our twin clinic, management of monochorionic twin pregnancies includes serial evaluations of fetal biometry, Doppler velocimetry, and biophysical profile, as well as monitoring of TTTS signs and amniotic fluid volume.

Ultrasound examination was performed transabdominally using a 3.5-5.0 MHz curvilinear-array transducer (Envisor - Phillips; Voluson Expert- GE). Fetal weight was estimated using the four-parameter formula (head and abdominal circumferences, biparietal diameter, and femur length) described by Hadlock et al.. ${ }^{9}$ Gestational age was estimated based on the date of the last menstrual period and on first-trimester or two consecutive second-trimester ultrasound scans. Selective IUGR was defined as estimated fetal weight below the $10^{\text {th }}$ percentile in one twin according to a nomogram for twins. ${ }^{8}$

Oligohydramnios was defined as the deepest vertical pocket (DVP) of $2 \mathrm{~cm}$ or less and polyhydramnios as the DVP of $8 \mathrm{~cm}$ or greater prior to 20 weeks and $10 \mathrm{~cm}$ or greater after 20 weeks. ${ }^{10}$ Diagnosis criteria for TTTS was considered as previously described. ${ }^{11}$ Chorionicity was determined by first-trimester ultrasound examination and/or pathoanatomical examination in all cases.

Doppler examination of the umbilical artery (UA) was performed in a free loop of the umbilical cord near the respective fetus. Whenever the UA was altered, evaluation was performed in three other areas of the umbilical cord. Abnormal UA Doppler was classified according to the characteristics of diastolic flow: ${ }^{5}$ type I (positive with increased pulsatility index, PI); type II (persistent absent or reversed end diastolic velocity flow, AREDF), and type III (intermittent absent or reversed end diastolic velocity flow, iAREDF).

Cases with IUGR but normal UA Doppler were followed every two weeks. Cases with abnormal Doppler and gestational age below 26 weeks were examined weekly. In our nursery, viability is considered after 26 weeks of gestation; therefore, cases with type I Doppler were monitored weekly and cases with type II or III were admitted to the hospital and monitored daily with Doppler velocimetry of UA, middle cerebral artery, and ductus venosus in combination with biophysical profile and fetal heart rate measurements. All cases were managed expectantly as they were not subjected to laser therapy or selective feticide.

Delivery indication due to fetal deterioration was considered before 28 weeks when there was AREDF in the ductus venosus; after this period, if any of the following parameters were present: ductus venosus PI persistently above $1.0,{ }^{12}$ persistently abnormal fetal heart rate traces, and maintenance of abnormal biophysical profile $(<6)$ in evaluations 6 hours apart. Cases with AREDF or iAREDF not presenting fetal deterioration were delivered at 34 weeks of gestation. For type I, in accordance with our protocol for monochorionic twin pregnancy, delivery was scheduled at 36 weeks or earlier if fetal deterioration was observed.

Indicated preterm delivery was carried out based on either maternal or fetal conditions. Prophylactic antenatal corticosteroids ( 2 daily IM $12 \mathrm{mg}$ betamethasone) were administered only if preterm delivery ( $<34$ weeks) was anticipated. All cases were delivered in our institution and the neonates were kept in the nursery adjacent to the maternity ward. The placentas underwent pathoanatomical examination; however, perfusion studies of the vascular shunts were not performed.

Major perinatal outcomes of the siblings in each group were compared. Outcome variables related to neonatal morbidity were gestational age at hospital admittance, gestational age at birth, birth weight, five-minute Apgar 
score $<7$, length of hospital stay, length of stay in neonatal intensive care unit (ICU), fasting time, orotracheal intubation, mechanical ventilation, and the presence of respiratory diseases (hyaline membrane, iatrogenic pneumothorax, emphysema, pulmonary hypertension, wet lung syndrome, pneumonia and/or bronchopulmonary dysplasia), infectious diseases (pneumonia, sepsis), neurological disorders (intraventricular hemorrhage, IVH; periventricular leukomalacia, PVL; multicystic leukoencephalomalacia), and blood disorders (anemia, neutropenia, polycythemia). Variables of perinatal outcome were also recorded, such as hospital discharge, intra-uterine death, and death during nursery admission.

The chi-square test or Fisher exact test were used to test the homogeneity of the groups in terms of proportions. Mean differences between the two groups were compared using Student $t$ test or Mann-Whitney test. The level of significance was set at $5 \%$ for all tests.

\section{Results}

Eighteen twins with sIUGR and 16 with nsIUGR were analyzed with respect to neonatal morbidity and mortality.

Mean maternal age was lower in the sIUGR group $(p<0.001)$. Otherwise, groups did not differ from each other: parity, previous miscarriages and rates of gestational diabetes mellitus, chronic hypertension, and preeclampsia were similar (Table 1).

Table 2 displays the neonatal morbidity and mortality data. It can be seen that mean gestational age at hospital admittance for control of fetal surveillance was lower in the sIUGR group $(\mathrm{p}=0.024)$ and that there was longer time of fasting in the nursery $(p=0.014)$ as well as a higher need for orotracheal intubation $(\mathrm{p}=0.001)$ and use of mechanical ventilation ( $\mathrm{p}=0.0006)$ among the newborns with sIUGR. Mean gestational age at delivery, mean birth weight and total length of nursery and neonatal ICU stay did not differ significantly between the two groups.

Three fetuses with restricted growth (2 with sIUGR and 1 with nsIUGR) progressed to IUDs; all had REDF in the umbilical artery (type II). One fetal death occurred at 26 weeks of gestation with ductus venosus PI equaling 1.44 at the last evaluation. The fetus was receiving corticotherapy for lung maturation; the non-restricted twin was also dead. Another fetus died at 28 weeks of gestation; the $d u c$ tus venosus $\mathrm{PI}(0.82)$ and biophysical profile parameters were normal 24 hours prior to death. The co-twin was delivered at 32 weeks of gestation (nsIUGR). In the third case, fetal death was diagnosed at 32 weeks of gestation, and, as in the previous case, the ductus venosus PI (0.85) and biophysical profile parameters were normal 24 hours prior to death; delivery of the co-twin was performed soon after detection of the fetal death of the growth-restricted one. There was no difference in the incidence of IUD and ND between the two groups ( $\mathrm{p}=0.092$; Table 2$)$.

Table 3 shows the distribution of Doppler velocimetry patterns in the sIUGR and nsIUGR groups. Type I UA Doppler velocimetry was more frequent in the nsIUGR group, whereas type II and type III UA Doppler velocimetry occurred more often in the sIUGR group.

\section{Discussion}

Although the two study groups were no different regarding gestational age at delivery and birth weight, the MCDA pregnancies complicated by sIUGR had a higher incidence of neonatal morbidity than the nsIUGR group.

TABLE 1 Characteristics of the study population. sIUGR = selective intrauterine growth restriction; nsIUGR = non-selective intrauterine growth restriction

\begin{tabular}{l|l|l|l} 
& sIUGR $(\mathbf{n}=\mathbf{1 8})$ & nsIUGR $(\mathbf{n}=\mathbf{1 6})$ & $\mathbf{P}$ value \\
\hline Male $(\mathrm{n}, \%)$ & $11(61.1)$ & $12(75.0)$ & $0.387^{*}$ \\
\hline Parity (mean, SD) & $0.33 \pm 1.50$ & $1.50 \pm 2.78$ & $0.429 * *$ \\
\hline Miscarriages (mean, SD) & $0.39 \pm 0.78$ & $0.13 \pm 0.35$ & $0.531^{* *}$ \\
\hline Maternal age (mean, SD) & $25.83 \pm 6.97$ & $35.00 \pm 7.07$ & $0.001^{* * *}$ \\
\hline Gestational diabetes (n, \%) & $2(11.1)$ & $2(12.5)$ & $1.000^{* * *}$ \\
\hline Chronic hypertension (n, \%) & $5(27.8)$ & $6(25.0)$ & $1.000^{* * * *}$ \\
\hline Preeclampsia (n, \%) & $7(38.9)$ & $6.933^{*}$ & \\
\hline
\end{tabular}

* Chi-square test.

** Parametric Mann-Whitney test.

*** Student $t$ test.

**** Fisher exact test. 
TABLE 2 Neonatal morbidity and mortality parameters in selective and non-selective intrauterine growth restriction (sIUGR; nsIUGR). GA: gestational age; ICU: intensive care unit

\begin{tabular}{|c|c|c|c|}
\hline & $\operatorname{sIUGR}(n=18)$ & nsIUGR (n=16) & $\mathrm{p}$ value \\
\hline GA at hospitalization (weeks, mean, SD) & $29.8(2.8)$ & $31.4(2.1)$ & $0.024 *$ \\
\hline GA at delivery (weeks, mean, SD) & $33.4(1.6)$ & $33.4(1.6)$ & $0.953 *$ \\
\hline Birth weight (g, mean, SD) & $1093.4(341.3)$ & $1274.7(264.7)$ & $0.111 * *$ \\
\hline Length of stay (days, mean, SD) & $35.2(10.2)$ & $45.4(34.8)$ & $0.707^{*}$ \\
\hline Neonatal ICU stay (days, mean, SD) & $14.7(16.0)$ & $21.9(19.4)$ & $0.271 *$ \\
\hline Fasting time (days, mean, SD) & $7.5(7.8)$ & $3.0(6.9)$ & $0.014^{*}$ \\
\hline Apgar $<7-5^{\text {th }}$ minute $(\mathrm{n}, \%)$ & $2(12.5)$ & $1(6.6)$ & $1.000 * * *$ \\
\hline Orotracheal intubation (n, \%) & $10(62.5)$ & $1(6.6)$ & $0.001 * * * *$ \\
\hline Mechanical ventilation ( $\mathrm{n}, \%)$ & $12(75.0)$ & $2(13.3)$ & $0.0006 * * * *$ \\
\hline Neonatal ICU (n, \%) & $13(81.2)$ & $9(60.0)$ & $0.252 * * *$ \\
\hline Infection (n, \%) & $10(62.5)$ & $7(46.6)$ & $0.376 * * * *$ \\
\hline Intraventricular hemorrhage (n, \%) & $3(18.7)$ & $5(33.3)$ & $0.433 * * *$ \\
\hline Blood disorders (n, \%) & $12(75.0)$ & $9(60.0)$ & $0.457 * * *$ \\
\hline Respiratory disease (n, \%) & $14(87.5)$ & $8(53.3)$ & $0.092 * * *$ \\
\hline Outcome & & & $0.092 * * *$ \\
\hline Intrauterine fetal death & $2(11.1)$ & $1(6.2)$ & \\
\hline Neonatal death & $6(33.3)$ & $1(6.2)$ & \\
\hline
\end{tabular}

\begin{tabular}{|c|c|c|c|c|c|}
\hline & \multicolumn{2}{|c|}{ SIUGR } & \multicolumn{2}{|c|}{ nsIUGR } & \multirow[t]{2}{*}{$p$ value } \\
\hline & $n$ & $\%$ & $n$ & $\%$ & \\
\hline Type I & 2 & 11.1 & 11 & 68.8 & 0.002 \\
\hline Type II & 11 & 61.1 & 4 & 25 & \\
\hline Type III & 5 & 27.8 & 1 & 6.2 & \\
\hline Total & 18 & 100 & 16 & 100 & \\
\hline
\end{tabular}

Fisher exact test

Selective IUGR was associated with postnatal need for intubation and mechanical ventilation and longer fasting time during nursery stay than that of the nsIUGR group.

The reports by Gratacos et al. ${ }^{4,5,13}$ showed that sIUGR is associated with intermittent UA flow pattern (type III) and that the type of Doppler alteration is related to the number and diameter of artery-artery anastomoses. That prompted us to investigate if there were any differences between the sIUGR and nsIUGR groups regarding Doppler flow pattern.

In our study, type II and type III UA Doppler flow patterns were more frequently in sIUGR twins than in nsIUGR twins. On the other hand, type I UA pattern was more often seen in nsIUGR twins than in sIUGR twins. Our findings led us to question whether sIUGR and nsIUGR arise from different mechanisms regarding placental angio-structure, the former being related to vascular communication, as described in previous studies, $3,5,14,15$ and the latter to placental insufficiency. Also, we wondered if the older maternal age in the nsIUGR-related cases is a predictor of placental insufficiency. The non-assessment of placental vascularization in our study, however, prevents the confirmation of these hypotheses.

All three IUD cases ( 2 cases of sIUGR and 1 case of nsIUGR) reported herein were associated with UA Doppler velocimetry type II (REDF). Our data agree with those by Ishi et al. ${ }^{16}$ who reported a higher risk for IUD and ND in IUGR cases with persistent AREDF. No difference was found between the study groups in relation to IUD or ND. However, our findings suggest a tendency towards higher mortality in the sIUGR group: a total of 8 cases of IUD and ND (44.4\%) as against the 2 cases in the nsIUGR group (12.5\%). A larger number of cases may be necessary to evaluate with greater certainty the seemingly discrepant mortality rates of the two groups. 
Our results were similar to those by Ishi et al. ${ }^{16}$ who observed a higher risk of death in cases below the $3^{\text {rd }}$ centile of the normal curve for singleton pregnancies, but instead, we chose to use a specific twin curve in order to identify the most severe cases. ${ }^{8}$

It was thus possible to observe, in the sIUGR group, a higher rate of neonatal morbidity and of severe UA Doppler velocimetry patterns, perhaps due to the greater seriousness of placental dysfunction as characterized by UA Doppler velocimetry (AREDF and iAREDF pattern - types II and III according to categorization by Gratacos et al.). ${ }^{5}$ Therefore, sIUGR points toward the need for closer fetal surveillance given the risk of neonatal complications and IUD in such cases.

The gestational age at delivery in sIUGR reported by previous studies ${ }^{16}$ was lower ( 32 weeks) compared to the present study (33.36 weeks), showing that less severe cases were included in our study owing to late referral of such cases to a tertiary center. Probably, several of the severe cases had died in utero before reaching our center.

The present study reflects data from a single tertiary Center without discrepancies in the management of the cases. Therefore, we present a small number of cases as compared to multicenter studies. ${ }^{5,13,16}$ However, we found significant association of sIUGR with mechanical ventilation and orotracheal intubation (0.97 and 0.94 , respectively).

The present series was not submitted to laser therapy or selective feticide, showing the natural evolution of the cases.

There are no studies comparing neonatal outcome in cases of sIUGR and nsIUGR in MCDA pregnancies. Gao et al., ${ }^{7}$ when evaluating IUGR in mono and dichorionic pregnancies, observed that monochorionicity was a risk factor for IUGR. In the present study, MCDA twin pregnancies with sIUGR presented higher rate of severe UA Doppler abnormalities leading to a worse neonatal prognosis compared to MCDA twin pregnancies with nsIUGR.

\section{Resumo}

Restrição de crescimento intrauterino em gêmeos monocoriônicos diamnióticos.

Objetivo: avaliar a morbidade e mortalidade neonatal em gestações monocoriônicas e diamnióticas (MCDA) acometidas pela restrição de crescimento fetal seletiva (RCFS) e não seletiva (RCFNS).

Métodos: os parâmetros de morbidade e mortalidade neonatais foram avaliados em 34 gêmeos com RCF (abaixo do percentil 10 de uma curva de crescimento para gê- meos): 18 com RCFS e 16 com RCFNS. O grupo com RCFS teve origem em 18 gestações, em que somente um feto apresentava RCF. O grupo com RCFNS teve origem em 8 gestações em que ambos os fetos apresentavam RCF. Foram excluídos deste estudo casos da síndrome da transfusão feto-fetal e malformações fetais.

Resultados: os gêmeos de gestações MCDA com RCFS apresentaram maior frequência de entubação orotraqueal $(\mathrm{p}=0,001)$, ventilação mecânica $(\mathrm{p}=0,0006)$ e maior tempo em jejum durante internação $(\mathrm{p}=0,014)$, quando comparados aos gêmeos de gestações MCDA com RCFNS. No grupo com RCFS, também foram observados maior frequência de tipos II e III de dopplervelocimetria de artéria umbilical $(p=0,002)$. Não houve diferença significativa entre os grupos quanto à mortalidade neonatal $(\mathrm{p}=0,09)$. Conclusão: em gestações gemelares MCDA, a RCFS representa maior frequência de alterações severas na velocimetria Doppler da artéria umbilical e piores resultados na morbidade neonatal.

Palavras-chave: gêmeos monozigóticos, doenças em gêmeos, retardo do crescimento fetal, fluxometria por laser Doppler, morbidade, recém-nascido.

\section{References}

1. Lewi L, Van Schoubroeck D, Gratacós E, Witters I, Timmerman D, Deprest J. Monochorionic diamniotic twins: complications and management options. Curr Opin Obstet Gynecol. 2003;15:177-94.

2. Machin GA: Vascular anatomy of monochorionic twin placentas; In: Blickstein I, Keith LG, editors. Multiple pregnancy: epidemiology, gestation \& perinatal outcome. $2^{\text {nd }}$ ed. Andover: Thomson Publishing Services; 2005. p. 193-200.

3. Lopriore E, Pasman SA, Klumper FJ, Middeldorp JM, Walther FJ, Oepkes D. Placental characteristics in growth-discordant monochorionic twins: a matched case-control study. Placenta. 2012;33:171-4.

4. Gratacos E, Lewi L, Carreras E, Becker J, Higueras T, Deprest J, Cabero L. Incidence and characteristics of umbilical artery intermittent absent and/or reversed end-fiastolic flow in complicated and uncomplicated monochorionic twin pregnancies. Ultrasound Obstet Gynecol. 2004;23:456-60.

5. Gratacos E, Lewi L, Munoz B, Acosta-Rojas R, Hernandez-Andrade E, Martinez $\mathrm{JM}$, et al. A classification system for selective intrauterine growth restriction in monochorionic pregnancies according to umbilical artery Doppler flow in the smaller twin. Ultrasound Obstet Gynecol. 2007;30:28-34.

6. Valsky DV, Eixarch E, Martinez JM, Crispi F, Gratacos E. Selective intrauterine growth restriction in monochorionic twins: pathophysiology, diagnostic approach and management dilemmas. Semin Fetal Neonatal Méd 2010;15:342-8.

7. Gao Y, Zhiming He, Yanmin L, Sun H, Huang L, Li M, et al. Selective and non-selective intrauterine growth restriction in twin pregnancies: high risk factors and perinatal outcome. Arch Gynecol Obstet. 2012;285:973-8.

8. Alexander GR, Michael K, Martin J, Papiernick E. What are the fetal growth patterns of singletons, twins and triplets in the United States? Clin Obstet Gynecol. 1998;41:115-25.

9. Hadlock FP, Harrist RB, Sharman RS, Deter RL, Park SK. Estimation of fetal weight with the use of head, body and femur measurements - A prospective study. Am J Obstet Gynecol. 1985;151:333-7.

10. Senat M, Deprest J, Boulvain M, Paupe A, Winer N, Ville Y. Endoscopic laser surgery versus serial amnioreduction for severe twin-to-twin transfusion Syndrome. N Engl J Med. 2004;351:136-44. 
11. Quintero RA, Morales WJ, Allen MH, Bornick PW, Johnson PK, Kruger M. Staging of twin-twin transfusion syndrome. J Perinatol 1999;19:550-55.

12. Francisco RPV, Miyadahira S, Zugaib M: Predicting $\mathrm{pH}$ at birth in absent or reversed end-diastolic velocity in the umbilical arteries. Ultrasound Obstet Gynecol. 2006;107:1042-7.

13. Gratacós E, Diemert A, Hecher K, Lewi P, Depres J. Clinical outcome and placental characteristics of monochorionic diamniotic twin pairs with early and late-onset discordant twin. Am J Obstet Gynecol. 2008;199:511e1-e7.

14. Lewi L, Cannie M, Blickstein I, Jani J, Huber A, Hecker K, et al. Placental sharing, birth weight discordance, and vascular anastomoses in monochorionic diamniotic twin placentas. Am J Obstet Gynecol. 2007;197:587e1-e8

15. Lewi L, Gucciardo L, Huber A, Jani J, Mieghem TV, Doné E, et al. Clinical outcome and placental characteristics of monochorionic diamniotic twin pairs with early and late-onset discordant twin. Am J Obstet Gynecol. 2008;199:511e1-e7.

16. Ishi K, Murakoshi T, Hayashi S, Saito M, Sago M, Takahashi Y, et al. Ultrasound predictors of mortality in monochorionic twins with selective intrauterine growth restriction. Ultrasound Obstet Gynecol. 2011;37:22-6. 